\title{
O quadro, o corpo e o espaço no cinema
} The frame, the body and the space in cinema

\author{
RACCA, Gustavo Badolati ${ }^{1}$ \\ ${ }^{1}$ Faculdade de Arquitetura e Urbanismo, Universidade Federal do Rio de Janeiro, Rio de Janeiro, Brasil. \\ gustavoracca@fau.ufrj.br \\ ORCID ID: 0000-0002-1763-8751
}

Recebido em 27/01/2020 Aceito em 31/01/2020

\section{Resumo}

A cidade é um objeto inacabado e culturalmente produzido. Seus espaços são definidos historicamente por meio dos conflitos estabelecidos pelos diferentes grupos socioculturais que a conformam. As disposições espaciais e suas representações referem-se com a maneira com que o corpo se relaciona com a cidade ao longo do tempo. Posto isso, entende-se que a representação cinematográfica do espaço é feita por meio do recorte delimitado por um quadro quando o cineasta mira a paisagem. Esse quadro denuncia, entre movimentos e permanências filmadas, a cartografia do percurso daquele que opera a câmera definindo a imagem cinematográfica. A câmera é entendida como um "aparelho" que, por suas características, condiciona a construção do quadro e, portanto, da própria representação fílmica. Para compreender a representação cinematográfica de um espaço, portanto, se faz necessário investigar o quadro fílmico, ciente de que ele pressupõe uma relação entre corpo, espaço e câmera.

Palavras-Chave: Cidade e cinema, corpo e cidade, representação, aparelho

\begin{abstract}
The city is an unfinished and culturally produced object. Its spaces are defined historically through the conflicts established by different socio-cultural groups that shape it. The spatial arrangements and their representations refer to the way in which the body relates to the city over time. That said, it is understood that the cinematographic representation of the space is made through the cutout delimited by a frame when the filmmaker aims at the landscape. This picture denounces, between movements and filmed stays, the cartography of the path of the one who operates the camera defining the cinematic image. The camera is understood as a "apparatus" that, due to its characteristics, determine the construction of the frame and, therefore, of the film representation itself. Therefore, in order to understand the cinematographic representation of a space it is necessary to investigate the filmic frame, being aware that it presupposes a relationship between body, space and camera.
\end{abstract}

Key-Words: City and cinema, body e city, representation, apparatus 


\section{Introdução}

A arquitetura e o urbanismo se firmaram como disciplinas dedicadas ao estudo das cidades e suas espacializações. O cinema, por sua vez, valendo-se das técnicas da fotografia em movimento concebe narrativas acerca da relação do homem com o ambiente que construiu e em que vive. No entanto, o que aproxima essas disciplinas é o fato de utilizarem o espaço como matéria-prima para suas ações e representações, como já colocado por autores como Jorge Luiz Barbosa (BARBOSA, 2000), Mark Shiel e Tony Fitzmaurice (SHIEL e FITZMAURICE, 2003), dentre outros.

A cidade, produzida e transformada ao longo da história a partir da cultura, é permanentemente objeto de inúmeras representações. Palco de embates e manifestações, ganha novos contornos à medida que as transformações socioculturais se espacializam. Os corpos que habitam a urbe, por sua vez, representam constantemente seus valores, atribuindo signos aos diferentes espaços das cidades. Diferentes manifestações artísticas são empregadas para representar esse espaço urbano em transformação, entre elas o cinema. A ideia de movimento que tanto caracteriza a imagem cinematográfica, vê eco na paulatina transformação dos padrões de comportamento dos corpos urbanos, especialmente a partir da revolução industrial.

Nesse artigo, parte-se do pressuposto que a representação cinematográfica ocorre sempre por meio da ação de um corpo que filma o espaço. Esse corpo percorre, se move, estaciona, mira e recorta a paisagem urbana e todos esses gestos que compõem o filme final são decorrentes das escolhas do cineasta. No entanto, para captar fragmentos da paisagem, o cineasta precisa empregar um aparelho, a câmera. Esse instrumento permite que estabeleça diferentes quadros que recortam elementos do espaço vivido a fim de rearticulá-los em forma de narrativa fílmica. Defende-se aqui, que a construção fílmica demonstra a ação dos corpos filmados (diante da câmera) delimitados por um quadro que, ao se mover, representa a própria ação do corpo que filma (atrás da câmera). Sendo assim, pela apreciação dos aspectos do enquadramento da imagem, é possível entender a representação do espaço em função dos corpos que o experimentam.

Esse trabalho busca contribuir com algumas reflexões no campo da arquitetura e do cinema. Para tanto, parte de uma breve leitura panorâmica do espaço urbano e suas relações históricas com as manifestações do corpo a partir de Richard Sennett (SENNETT, 2016). As reflexões desse autor contribuem para entender como os comportamentos do corpo citadino se alteram ao longo da história das cidades. As disposições espaciais na cidade são modificadas à medida que os padrões de deslocamento e de produção demandam corpos agitados e em constante movimento. Nesse contexto, vinculado à ideia de movimento e velocidade, surge o cinema que se firma como um dos principais meios de representação do espaço urbano.

Em seguida, discute-se a representação do espaço urbano articulando seus aspectos nos campos do cinema e da arquitetura. Estabelece-se uma relação entre a noção de "quarta dimensão" proposta por Bruno Zevi (ZEVI, 1996) e a ideia de "visão serial" em Gordon Cullen (CULLEN, 1983) para se propor aproximações com a representação do espaço no cinema. Essa questão impõe a necessidade de problematizar a questão do quadro que conforma a imagem cinematográfica e como ela se particulariza ao reproduzir a ideia de movimento - dentro e fora do campo delimitado por este enquadramento. A noção de quadro no cinema, ganha novos contornos nessa discussão principalmente por evidenciar não somente o movimento daquilo que filma, como também o movimento do próprio cineasta quando segura a câmera e percorre o espaço que busca representar.

Por fim, coloca-se brevemente a questão do aparelho e do funcionário, conceitos cunhados pelo filósofo Vilém Flusser (FLUSSER, 2011), por entender que tanto a construção do quadro no cinema como o movimento do corpo que empunha a câmera estão diretamente vinculados às características 
desse aparelho de filmar. As limitações de suas características internas (ou seu "programa" como descreve o autor) condicionam o corpo que filma a estar e/ou se mover no espaço de maneira específica influenciando, assim, a imagem cinematográfica resultante. O espaço filmado é o espaço vivido e registrado pelo corpo do cineasta sempre em função de sua relação com o aparelho que utiliza.

Neste trabalho, procura-se evidenciar, por meio de algumas breves análises fílmicas, o processo de produção cinematográfica como uma experiência essencialmente corporal pelo espaço. Dessa forma, busca-se também, reconhecer a representação cinematográfica do espaço como um registro de uma relação pautada pelo espaço, o corpo e o aparelho que filma, admitindo o estabelecimento do "quadro" cinematográfico como sua manifestação na imagem fílmica.

\section{2. $O$ corpo e a cidade}

A cidade, objeto inacabado e heterogêneo, como afirmam os geógrafos Roberto Lobato Corrêa (CORRÊA, 1993) e Milton Santos (SANTOS, 2006), está em permanente transformação, compreendida, assim, como elemento sujeita aos diferentes aspectos culturais que conformam as sociedades humanas. Como em qualquer representação, o desenho das cidades assume ao longo da história diferentes características fruto dos conflitos, interesses e demandas socioculturais. Sendo assim, a cidade pode ser compreendida, também, como arena em que são mediados os embates entre indivíduos que constantemente disputam seus espaços por meio de suas representações.

A arena que constitui os espaços da cidade abriga corpos em pleno exercício das mais variadas manifestações, sejam elas políticas, artísticas, festas, danças, percursos, protestos etc. Disputar o espaço urbano dotando-o de significados que o adequem aos padrões culturais que constituem as sociedades, pressupõe essencialmente ações do corpo sobre esse espaço. Estar, mover-se, gritar, construir ou destruir são, por excelência e a priori fruto de variadas atividades corporais do indivíduo no meio em que habita. É, portanto, possível compreender os elementos que caracterizam a cidade através, também, da leitura de suas representações através do corpo. Como os corpos se comportam no espaço urbano? Como se movem? A que corpos esses espaços atendem? Que ações eles permitem? Que ações intimidam?

A relação entre o corpo e a cidade se constitui como campo fértil no âmbito da arquitetura e, mais especificamente, do urbanismo. Richard Sennett (SENNETT, 2016), por exemplo, em seu livro Carne e Pedra adota o corpo humano como categoria para analisar os processos históricos que pautam as transformações nos desenhos das cidades, bem como em sua conformação socioespacial. Esse autor argumenta que as maneiras de organizar os espaços urbanos ao longo da história estão sempre intimamente ligadas aos significados atribuídos ao corpo que os habitam. Na Atenas de Péricles, por exemplo, os espaços públicos de maior relevância para o conjunto social eram pensados para o pleno exercício da noção de democracia que os atenienses tinham à época. A ágora constituía espaço amplo para que o a população da cidade pudesse permanecer e ter suas demandas expostas através do grito e do acaloramento de seus corpos em grandes debates. Essa prática, tão cotidiana da vida ateniense no século $V$ a.C., expõe como na antiguidade o espaço público exercia crucial importância social e que, para o exercício de suas manifestações culturais, precisava ser desenhado para permitir a permanência e articulação de diferentes grupos.

Sennett parte sua análise desde a antiguidade até a era moderna. Sua intenção é justamente conduzir para a compreensão de como o caráter das cidades, para além do inchamento de suas dimensões físico-espaciais, está diretamente ligado às maneiras com que os corpos se agrupam, permanecem ou se deslocam pelo espaço. Assim, em meio ao panorama espaço temporal que traça em seu livro, cabe destacar não somente sua análise de Atenas governada por Péricles (por onde inicia suas 
investigações), passando por Roma no início da ascensão do cristianismo, a Veneza renascentista que passa a "guetificar" os corpos em função de padrões econômicos e religiosos, como também a populosa Nova York na modernidade.

Esse artigo não tem a intensão de debater minuciosamente a referida obra de Richard Sennett. No entanto, parte de seu panorama histórico amparado na leitura dos corpos na cidade para entender como as representações, em especial o cinema, guardam relações intrínsecas com o próprio comportamento dos indivíduos no espaço urbano. O sociólogo, à medida que conduz sua análise à modernidade citadina, se aproxima paulatinamente da noção de que os ambientes urbanos passam a cercear os sentidos do corpo ao mesmo tempo em que se celebra maior mobilidade e capacidade locomotora pela cidade, especialmente após a revolução industrial.

A lógica da eficiência e a própria noção de saúde urbana na modernidade tem suas bases fundamentais muito vinculadas à ideia de movimento dos corpos. Amparadas às então novas descobertas das ciências médicas de que o corpo humano saudável mantém um fluxo sanguíneo constante, as primeiras noções de saúde urbana, no âmbito do que viria a se chamar, enquanto disciplina, de "urbanismo", também passam a preconizar o constante movimento dos seus corpos. Os novos planos para as cidades ocidentais, cada vez mais populosas, partem dos desenhos de suas vias a fim de garantir o pleno escoamento de suas produções e de seus trabalhadores. Se em momentos anteriores da história das cidades a praça era elemento primordial para 0 desenho dos espaços urbanos, após a revolução industrial a rua passa a protagonizar o seu planejamento, encarando as urbes a partir de então como "grandes corpos" a serem diagnosticados e tratados. Seu traçado, repleto de "veias" e "artérias", passa a objetivar ininterrupto fluxo de seus corpos sob o risco de adoecer.

Essa compreensão de que a cidade deve garantir a permanente circulação leva Sennett a compreender que o espaço público deixa de assumir protagonismo como lugar de permanência e, portanto, de troca e tolerância entre os seus indivíduos, para vincular-se a noções como locomoção e escoamento. O movimento nas metrópoles modernas afasta o homem do convívio e do contato interpessoal. A comunicação coletiva e constante troca de informações nos espaços coletivos dão lugar ao silêncio nos meios de locomoção urbana. Há uma mudança de paradigma na vida urbana associada aos avanços científicos, ao crescimento da produção industrial e aos processos migratórios para os grandes centros levando ao seu aumento populacional. Não por acaso, nesse mesmo contexto surgem novas formas de representação e, mais especificamente novas formas de produção imagética. As representações "tradicionais" não davam mais conta de captar as novas relações do corpo humano e o espaço citadino em que habita.

A estatuária, a pintura, a própria arquitetura que, em grande medida anunciavam os códigos de comportamento dos corpos humanos desde a antiguidade, enfrentam novos desafios ao se deparar com a cidade industrial repleta de locomotivas, chaminés fabris em plena atividade, multidões se deslocando nas ruas, largas vias atravessadas por carros etc. As representações artísticas desse momento histórico, assim como o comportamento dos corpos urbanos, se alteram ou, pode-se argumentar, demandam por novas maneiras de captar e apresentar o mundo. Nesse contexto, nasce a fotografia e, posteriormente, o cinema, manifestações artísticas essencialmente industriais e urbanas. Também a fotografia, mas especialmente o cinema, acabam por se tornar as representações da vida urbana por excelência. Sua capacidade de captar e reproduzir as noções de velocidade e movimento à imagem, de mostrar ao indivíduo o comportamento dos corpos urbanos a partir de novas perspectivas acabaria por ilustrar consideravelmente a modernidade.

O cinema enquanto manifestação artística denota a relação do corpo com o espaço urbano da modernidade e isso pode ser apreciado de duas maneiras principais: o corpo filmado e o corpo que 
filma. Nas duas abordagens se trata da representação da ideia de percurso dos corpos pela cidade e, em ambas, o recorte estabelecido pelo enquadramento da câmera se configurará como elemento chave para percepção dos seus movimentos, como se verá a seguir.

\section{Cinema e a representação do espaço urbano}

$\mathrm{Na}$ virada dos séculos XIX e XX, momento em que autores como Francis Vanoye e Anne Goliot-Lété (VANOYE e GOLIOT-LÉTÉ, 2005) descrevem como o cinema dos primeiros tempos, os filmes apresentavam um comprometimento, ou mesmo um fascínio, pela própria capacidade de reproduzir a ideia de movimento através da ilusão de ótica alcançada pela captação e exibição de vários frames a cada segundo. Paralelamente o cinema assume caráter documental ao captar cenas do próprio cotidiano das cidades. O movimento dos trens, a entrada e saída das multidões das fábricas e o incessante trabalho das máquinas constituíam, dentre outras imagens, o acervo cinematográfico dos seus primeiros anos.

Aos poucos a linguagem cinematográfica vai se desenvolvendo a ponto de garantir novas maneiras de representar o espaço: o som indireto é associado às imagens como recurso de linguagem, a câmera parada ganha movimento, a captação de som direto permite entrevistas e diálogos mais consistentes, enfim, a narrativa cinematográfica assume novos contornos a medida que novos recursos de tecnologia de captação e exibição fílmica se desenvolvem e são incorporados ao processo de produção.

Dentre os muitos avanços tecnológicos que possibilitam reformulações na narrativa cinematográfica cabe aqui destacar um elemento em especial: o movimento de câmera. Quando o cineasta levanta a câmera pela primeira vez do tripé e a coloca em movimento enquanto filma consegue reproduzir na imagem final seu percurso pelo espaço. Seu ponto de vista, anteriormente estático, ganha outra dimensão ao poder reproduzir os movimentos do seu corpo pelo espaço que filma e que representa. Para as disciplinas comprometidas a debater a representação espacial, como a arquitetura e o urbanismo, por exemplo, novas possibilidades de investigação se apresentam. Talvez se possa argumentar que, enquanto meio de representação, tal feito coloque questões de relevância similar às que a perspectiva cônica colocou no Renascimento.

A emancipação da câmera em relação ao tripé, ou seja, de seu caráter estático, não configura um gesto banal como pode aparentar. Os avanços técnicos que tornam mais fácil segurar a câmera com as próprias mãos ao filmar garante ao cineasta não somente a possibilidade de captação do movimento dos corpos a sua frente como permite que seu próprio corpo interaja mais declaradamente com o espaço. Diferentes movimentos estéticos do cinema passariam a explorar essa característica como o Cinema Direto e o Cinema Verdade, por exemplo. A representação do movimento pelo espaço em primeira pessoa, por sua vez, atualiza a discussão sobre o tema no campo da arquitetura que até então tem no desenho o eixo central do seu eixo representacional.

$\mathrm{Na}$ teoria da arquitetura e do urbanismo é frequente o debate em torno da singular maneira com que este campo do conhecimento apreende, representa e edifica os espaços. Admite-se que o espaço não seja uma categoria exclusiva da arquitetura, especialmente se, assim como os geógrafos, parte-se da compreensão de que as relações socioculturais conformam espacialidades e Ihes atribuem significados a todo instante.

De toda maneira, o espaço enquanto categoria de análise e matéria prima da produção da arquitetura é constantemente revisitado conceitualmente na incessante busca pela delimitação da arquitetura enquanto campo autônomo. Esse tema não está sendo aqui abordado diretamente, mas parte-se do pressuposto que o cruzamento entre campos de conhecimento seja vital para uma mais profunda 
compreensão dos aspectos que conformam as muitas relações desse e nesse espaço.

O teórico de arquitetura Bruno Zevi (ZEVI, 1996) se debruçou sobre o tema a fim de melhor definir a noção de espaço, especialmente no âmbito da arquitetura, mas também no urbanismo. Para o autor, quando escreve o livro Saber ver arquitetura em 1948, as categorias constantemente utilizadas para a apreciação (seja por leigo ou um profissional) das "qualidades" arquitetônicas são insuficientes para dar conta da complexidade da fruição espacial tal qual permitida pela experiência arquitetônica. Consequentemente, o sistema de representações gráficas constantemente utilizado para descrevê-la e, portanto, projetá-la, acabam se mostrando relativamente falhos ou, no mínimo, limitados. Para Zevi, "todas as obras de arquitetura, para serem compreendidas e vividas, requerem o tempo da nossa caminhada, a quarta dimensão" (ZEVI, 1996, p. 23) e, com isso, reconhece a representação cinematográfica como potencial instrumento à arquitetura.

A dimensão espacial da arquitetura, para esse autor, não se assemelha à discussão do espaço em outras manifestações artísticas. Na pintura as noções de profundidade foram exaustivamente exploradas até a (re)descoberta da perspectiva no Renascimento. Como descreve Zevi, nesse período acreditava-se que as dificuldades para a representação da tridimensionalidade e volumetria dos objetos estaria superada e que, portanto, todas as demandas para a representação espacial da arquitetura estariam resolvidas. Mas, como coloca o autor, há um fator intrínseco à espacialidade na arquitetura que jamais seria solucionado por qualquer figura plana, estática e bidimensional, por mais fiel que sua construção perspectiva remeta à realidade. Em qualquer gravura, pintura ou desenho em perspectiva é rigorosamente estabelecido um ponto de vista que simula o olhar de um observador inserido no espaço. No entanto, a verdadeira experiência espacial na arquitetura deverá considerar o complexo conjunto de experiências sensoriais que se dão à medida que esse observador se movimenta e percebe constantes diferenças a cada troca de olhar. Mesmo o observador estático no espaço estará sempre sujeito à uma série de modificações no ambiente que alteram sua percepção seja pela variação da luz ao seu redor, seja pela presença de sons, odores etc.

Essa complexa rede de experiências sensoriais vivenciadas a cada variação de ponto de vista ao longo do espaço configura o que Zevi chama de quarta dimensão do espaço e que nenhuma imagem estática terá condições de representar. A partir de suas teorias, compreende-se que a apreciação da quarta dimensão, por sua vez, pressupõe a existência de dois elementos fundamentais: o tempo e o corpo. Sujeito aos acontecimentos no tempo, o espaço se modifica permanentemente à medida que o observador se desloca e experimenta a arquitetura. Paralelamente o observador que se move pelo espaço o percebe sempre por meio de um complexo espectro de sensações e essas sensações não se limitam à visão. Portanto, pode-se afirmar que a quarta dimensão que caracteriza a experiência espacial da arquitetura é essencialmente uma experiência corporal no tempo.

Outra abordagem que parte de pressupostos similares é do arquiteto Gordon Cullen (CULLEN, 1983) em seu livro A Paisagem Urbana. Nele, propõe a "visão serial" como metodologia de análise do espaço (no caso mais especificamente o urbano) por meio do registro de diferentes momentos do percurso do observador. Trata-se do congelamento, através de desenhos, de recortes da paisagem a medida em que observador caminha por um percurso. Associa-se a esses registros um pequeno mapa que ilustre o percurso adotado (figura 1). Para ele a riqueza na percepção do espaço ligava-se às surpresas que se revelavam ao longo de um deslocamento. Descreve a sucessão de "imagens existentes" e "imagens inexistentes" à medida que o observador se desloca. $O$ frequente contraste entre essas duas categorias permite, segundo Cullen, qualificar o espaço segundo a percepção da paisagem. 
Figura 1: A Visão Serial proposta por Gordon Cullen (Fonte: CULLEN, 1983).
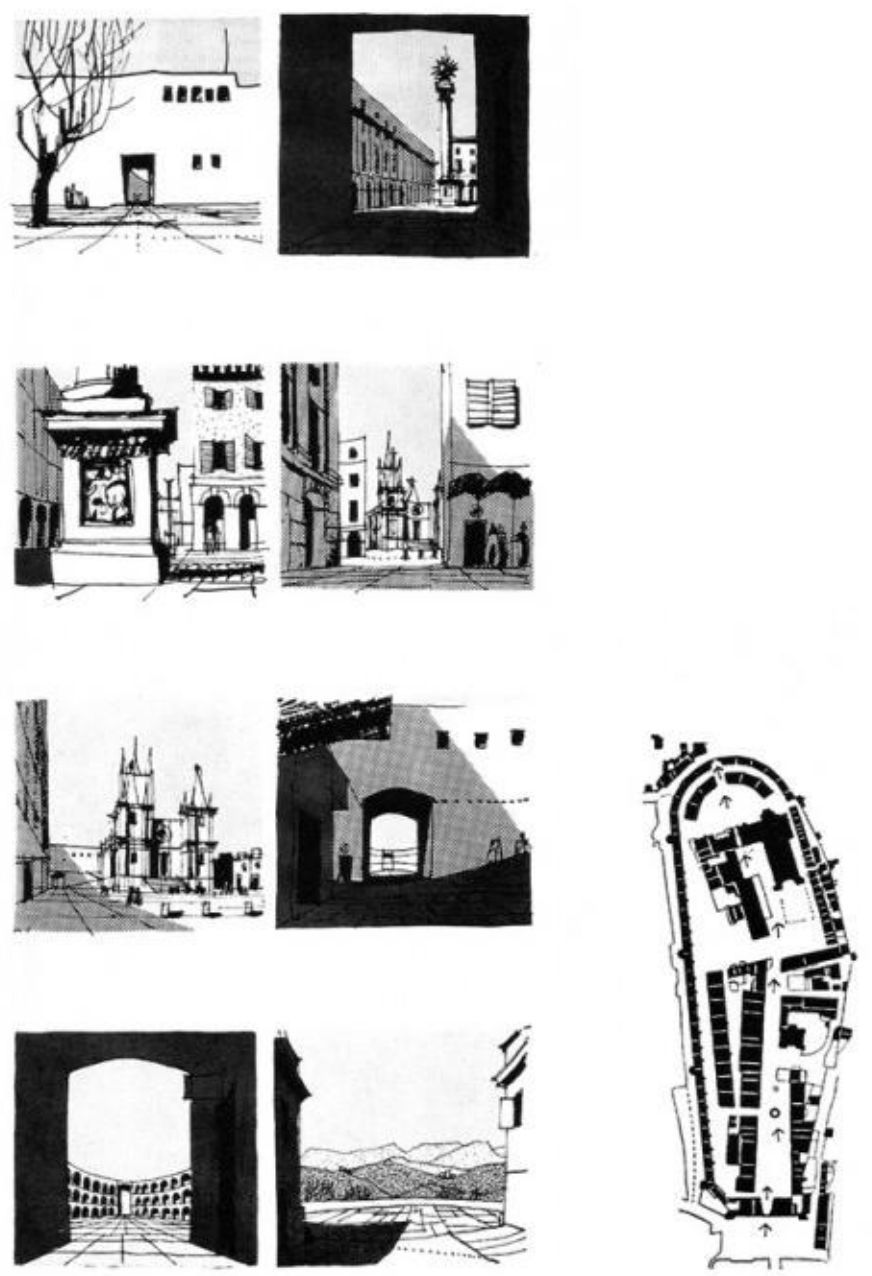

Tanto a abordagem teórica de Bruno Zevi quanto a abordagem prática de Gordon Cullen remetem diretamente à representação cinematográfica do espaço. O primeiro, ao defender que o tempo é elemento chave para a percepção espacial e o segundo ao tentar reproduzi-lo "frame a frame". Suas descrições são extremamente cinematográficas e não podem ser compreendidas sem se levar em consideração o papel do corpo na experiência. O percurso pela cidade é extremamente caro aos pesquisadores urbanos no século XX e, não por acaso, o cinema os fascinou tanto. Os filmes representam o percurso e a temporalidade com que o corpo experimenta o espaço vivido e, com isso, produzem posteriormente asserções sobre essa experiência naquele que assiste ao filme.

A questão do contraste entre imagens existentes e inexistentes proposta por Cullen remete, também, à montagem (ou edição) na etapa de pós-produção cinematográfica. Sergei Eisenstein (EISENSTEIN, 1990a, 1990b) e André Bazin (BAZIN, 1991), por exemplo, embora discordassem sobre a importância ideológica da montagem na representação cinematográfica, dedicaram grande parte da suas investigações ao estudo dos efeitos da montagem do filme. $O$ processo de corte e cola de planos filmados pode ser descrito como a articulação de uma "fita de tempo". Sendo assim, o encadeamento desses planos no filme final eleva a condição do corpo representado que passa, assim, a transitar 
entre espaços e temporalidades ao longo da narrativa. A articulação desses fragmentos desdobra-se em uma outra representação enquanto filme finalizado, produzindo distintas imagens e variados efeitos perceptivos a depender daquele que $o$ assiste.

O plano fílmico que pode ser entendido como uma espécie de "matéria prima" da representação cinematográfica - que reproduz o movimento de corpos filmados e corpos que filmam, que se articula em variadas "fitas de tempo" - é, por sua vez, sempre concebido a partir de um enquadramento. Compreender os limites desse quadro que seleciona o que conformará o campo visual é de suma importância para entender a representação do espaço no filme.

\subsection{O quadro}

A representação cinematográfica compreende, em geral, a projeção de imagens sobre uma superfície plana, geralmente a tela do cinema. Essa imagem que se configura como recorte da paisagem à frente do cineasta, promove constantemente asserções do espectador com a realidade fazendo-o compreender, entre outras questões, a tridimensionalidade do mundo representado e os aspectos socioculturais que têm lugar no espaço. Como anteriormente visto, através da ideia de movimento promovida pelo sequenciamento de imagens e, principalmente a partir das variadas movimentações de câmera, o cinema aproxima essas representações do que Bruno Zevi (ZEVI, 1996) considera como característica essencial da apreciação do espaço arquitetônico: a quarta dimensão.

Esse elemento (largamente explorado na pintura a partir do movimento cubista), no campo da arquitetura caracteriza-se, segundo Zevi, a partir dos percursos de um determinado indivíduo e o decorrente sequenciamento de pontos de vista para conformar uma única apreciação do espaço experimentado com o corpo. A descrição do autor para a quarta dimensão na arquitetura, ao contrário de sua característica em outras manifestações artísticas, pode ser entendida como essencialmente cinematográfica. O percurso do cineasta pelo espaço com câmera na mão faz com que o filme seja o meio de representação que mais se aproxima da apreciação da arquitetura pela experiência corporal. Essa imagem cinematográfica, no entanto, é sempre delimitada por um quadro e a relação constante entre ele e os elementos que surgem ou somem dos seus limites, particularizam a representação do espaço no cinema.

Embora as condições impostas pelo enquadramento já sejam amplamente discutidas no campo da percepção visual (ARNHEIM, 1980), no cinema assumem novos contornos devido a dois fatores principais: em primeiro lugar pelo constante movimento dos elementos delimitados pelo quadro e, em segundo lugar, pela movimentação do próprio quadro. O teórico de cinema Jacques Aumont (AUMONT, 1993, 1995) defende que o quadro cinematográfico delimita duas naturezas espaciais na representação fílmica: o "campo" e o "fora de campo" e que, consequentemente, a imagem cinematográfica se emancipa das demais produções imagéticas especialmente devido à constante relação estabelecida entre os dois. Elementos do espaço filmado se anunciam ainda fora do campo visual por meio do som, por exemplo, e são eventualmente revelados (ou não) pelo movimento de câmera empregado por aquele que filma. A compreensão do quadro no cinema permite reconhecer a reprodução do registro de um olhar, mas também dos percursos que o corpo do cineasta, ávido por informação desenha no espaço. 
Figura 2: A noção de "campo" e "fora de campo" a partir da delimitação do "quadro".

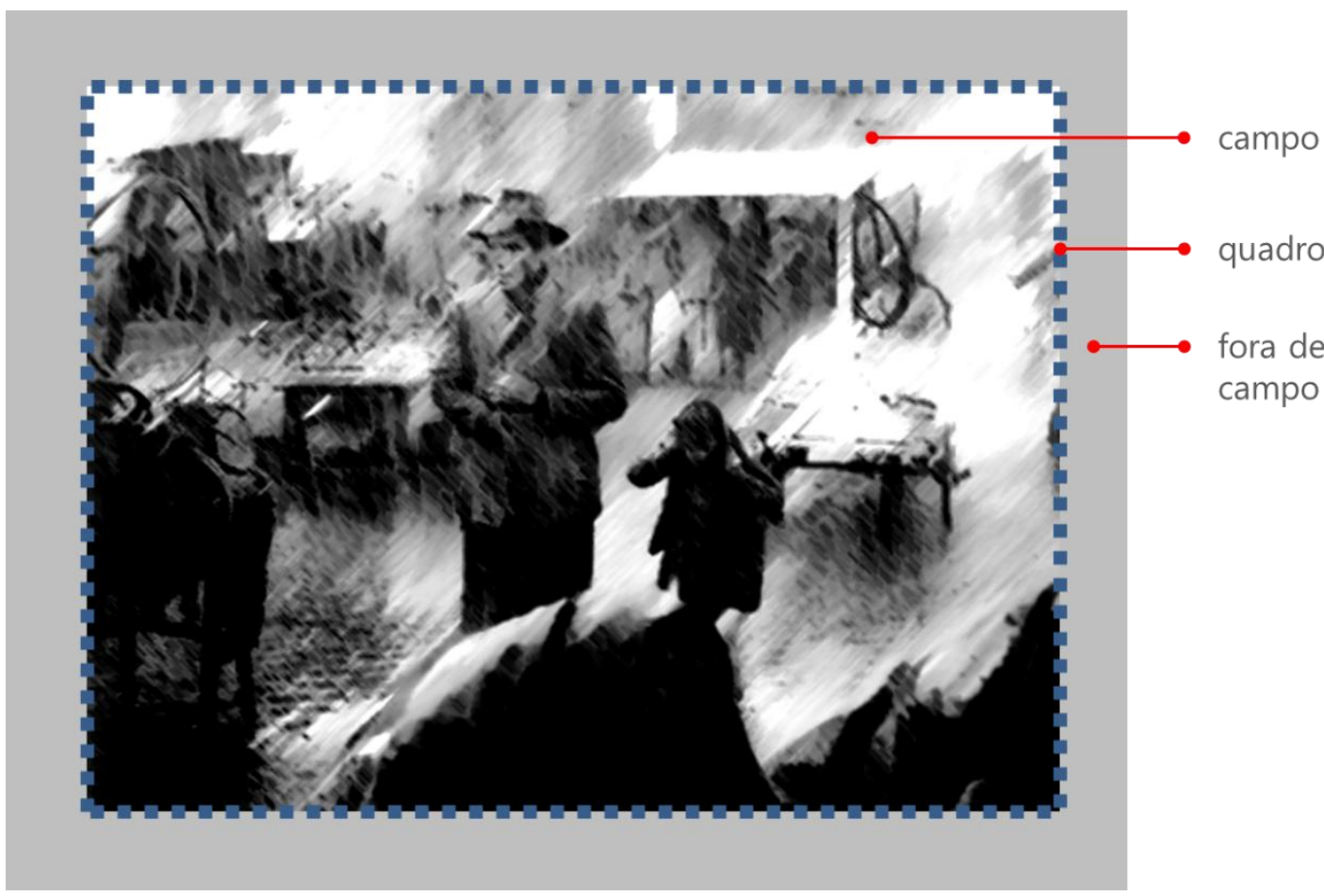

O quadro corta o espaço, secciona o visível para conceber, por meio da montagem, uma noção de espaço particular, fruto das intenções daquele que filma. A noção de campo, descrita por Aumont, está para o cinema como a noção de imagem existente, ou seja, faz parte do espectro visível da imagem cinematográfica. Da mesma forma, aquilo que está fora de campo, passível de adentrar o espectro visual a todo instante, se assemelha ao que Cullen descreve como imagem inexistente. A relação entre o que se encontra em campo e fora de campo se altera a todo instante no decorrer do fluxo narrativo do filme e isso ocorre em grande medida devido ao constante movimento de corpos filmados e, especialmente pelos movimentos impostos pelo corpo que filma. Este último interessa especialmente nessa discussão pois pressupõe a própria movimentação do quadro.

A construção do quadro no filme, bem como sua movimentação pelo espaço pressupõe uma série de escolhas daquele que filma. Essas escolhas demandam a utilização de diferentes câmeras e lentes, por exemplo. Tome-se como caso a seguinte sequência cinematográfica: abre-se um grande plano da cidade, em som externo ouve-se os sinos de uma catedral, em seguida o quadro se move a fim de apresentar um panorama mais amplo do quadro inicial, por fim, após um corte, a torre sineira ocupa todo o quadro demonstrando de onde vem o som inicial. Nessa sequência hipotética, todos os processos que envolvem o quadro do filme demandam o intermédio de um aparelho. O primeiro plano da cena pressupõe a escolha de uma lente específica que garanta a exibição de um grande panorama da cidade. Em seguida, seu movimento precisa ser construído pelo movimentar dessa câmera pelo espaço (em torno de um tripé ou com as próprias mãos). O último plano, o da torre sineira, por sua vez, faz crer que o cineasta modificou sua objetiva para alcançar o detalhe a uma distância maior, se moveu para se aproximar do objeto, ou adotou ambas as estratégias conjuntamente. Essa breve descrição contempla a presença de três elementos operando simbioticamente no espaço filmado a fim de representá-lo: o corpo do cineasta, o quadro da imagem resultante e o aparelho que utiliza para filmar.

Por meio desses três elementos, o registro cinematográfico do espaço pode ser entendido, portanto, como um registro do corpo daquele que filma através do espaço e, assim, desdobra cartografias 
mentais, simbólicas e afetivas no espectador que, ao assistir, (re)representa o espaço a partir de seu próprio referencial sociocultural. A representação fílmica é aqui entendida como manifestação da relação do corpo e a cidade, sempre intermediada por um aparato técnico denominado câmera.

\section{4. $O$ aparelho que filma}

Como visto, a imagem cinematográfica é caracterizada pela existência de um quadro e que esse quadro pode se mover ou não. Além disso, esse quadro delimita dois elementos que conformam a imagem cinematográfica: o campo e o fora de campo. O recorte da paisagem estabelecido pelo quadro no cinema pode ocorrer de diferentes maneiras e conformará em grande medida a linguagem do filme e as escolhas do cineasta que representa o espaço a sua frente. Esse recorte pressupõe, não somente a escolha do que aparecerá aos olhos do espectador quando da exibição do filme, como também a eliminação no espectro visual, de todo o restante que originalmente se apresentava ao operador da câmera.

Esse gesto, a delimitação do quadro, seu formato, seus movimentos, os elementos que se apresentarão a sua frente, ou seja, toda essa sucessão de escolhas no ato de filmar só pode ocorrer porque entre o cineasta e o espaço ao seu redor está um aparelho: a câmera. Embora possa parecer óbvia essa afirmação, sua compreensão é crucial para a leitura da imagem cinematográfica e, portanto, para a representação do espaço no filme.

O filósofo tcheco-brasileiro Vilém Flusser $(2011,2015)$ dedica-se ao estudo da imagem por meio de seus modos de produção. Enquanto autores como Roland Barthes (BARTHES, 2015) fazem imprescindíveis contribuições para a análise da imagem fotográfica a partir da interpretação dos elementos apresentados nela, Flusser discorrerá sobre o tema a partir da investigação da relação entre o indivíduo que produz a imagem e o que utiliza para tal. Isso porque, para esse filósofo, a imagem fotográfica e a cinematográfica não podem mais utilizar as mesmas categorias das imagens tradicionais porque essas "imagens técnicas" não podem ser produzidas sem a operação de um aparelho, no caso, a câmera.

Flusser argumenta que este aparelho, dotado de um "programa" interno, sempre coloca limites àquele que o manuseia. Este, a que o filósofo chama de "funcionário", está sempre sujeito às condicionantes impostas pelo aparelho neste eterno jogo de informação que configura os gestos fotográfico e cinematográfico. Em uma relação dialética, cineasta e câmera - ou funcionário e aparelho -, estabelecem constante embate e, por isso, as condições que pautam o percurso registrador do corpo fílmico pelo espaço estão sempre atreladas a ela.

A câmara, ou o aparelho, funciona como uma caixa preta. Seu funcionário não domina seu programa interno limitando-se a conceder elementos a ela na espera de que Ihe devolva uma imagem. $\mathrm{Na}$ constante experimentação, o funcionário constrói acervo de elementos ou modos de operar o aparelho para que Ihe devolva as imagens que deseja. Quando isso não é possível, o funcionário necessita "vencer" a programação original desse aparelho para que produza uma nova imagem.

O jogo descrito por Flusser para a concepção de imagens técnicas (fotografias, filmes etc) condiciona o funcionário às limitações programáticas do aparelho que utiliza. Sendo assim, pode-se argumentar que a representação fílmica é fruto de suas escolhas, mas também das possibilidades que o aparelho empregado apresenta. Com isso, a própria maneira de se movimentar no espaço a fim de representálo pelo cinema, estará sujeita ao tipo de aparelho utilizado. Por exemplo, o filme de Dziga Vertov, $O$ homem com a câmera, produzido em 1929 dispunha de recursos técnicos consideravelmente diferentes dos de Buena Vista Social Club de 1999, dirigido pelo cineasta alemão Wim Wenders. A câmera empregada por Vertov é consideravelmente mais pesada, operada por uma manivela. Sua 
representação do espaço urbano é feita por meio de grandes sequências em que a câmera se encontra parada apoiada em um tripé. Os movimentos que o quadro faz referem-se ao posicionamento da câmera sobre algum meio locomotor, como um carro. O filme de Wenders, por sua vez, mostra a cidade de Havana através de alguns de seus principais ícones musicais. Para ele a cidade é expressa pela música que toca nas ruas e nos bares. Para representar esses elementos a câmera é manuseada com mais liberdade que a de Vertov, reproduzindo, por vezes, o caminhar do cineasta pelos espaços e sua aproximação, como quem conversa com os indivíduos.

Nos exemplos apresentados fica claro que não se trata apenas de uma decisão estética de um cineasta ou do outro para a construção de suas respectivas narrativas fílmicas. Suas escolhas estão, em grande medida, também fundamentadas na tecnologia que dispunham em seus respectivos tempos históricos. Dziga Vertov provavelmente não seria capaz de se aproximar das investigações espaciais na escala humana, como fez Wim Wenders, entre outros motivos, porque não dispunha do mesmo aparelho e, portanto, das mesmas condições para a representar o espaço.

Em outro exemplo, a representação fílmica de Berlim por Walter Ruttmann em Berlim Sinfonia da Metrópole em 1927 é rigorosamente distinta da produzida em 1961 por Jean Rouch e Edgar Morin em Paris no documentário Crônicas da Cidade. Não apenas tratam de diferentes espaços urbanos e temporalidades distintas, mas paralelamente a isso, os recursos tecnológicos são consideravelmente outros. A pesada câmera sobre tripé utilizada por Ruttmann, em uma dupla relação, limitava seu corpo de caminhar pelo espaço ao mesmo tempo que emprestava as condições necessárias para sua representação totalizadora do espaço urbano industrial da capital alemã. No referido caso francês, o filme integrante do dito cinema verdade, é resultado de condições tecnológicas que permitiram aos cineastas caminharem pelas ruas, reproduzirem o movimento de seus corpos e o diálogo com os habitantes da metrópole francesa. O som direto é crucial nesse caso e ausente no primeiro, gerando maneiras distintas de olhar para a cidade e, consequentemente representá-la. Os dois filmes falam de seus tempos ao representarem o espaço urbano, não somente a partir do tema, mas, também, devido aos recursos estéticos e linguísticos possibilitados pelos aparelhos que dispunham.

O percurso do cineasta não é um percurso qualquer. Seu movimento pelo espaço urbano, além de produzir cartografias afetivas e constantemente memórias no corpo do cineasta, documenta imagens na forma de filme o que possibilita incontáveis exibições e reexibições. Para tanto, o corpo que filma está sempre munido de uma câmera que registra os elementos espaciais e produz as imagens em movimento.

\section{Conclusão}

Entender os filmes como representações do espaço exige, de antemão, compreender que os espaços são conformados por mais do que suas disposições físico-espaciais. O espaço é estabelecido por relações que constantemente atribuem significados às experiências, corpos, ações sons etc. O cinema, enquanto manifestação artística, apresenta importantes características que permitem a representação dessas relações. Os corpos que habitam o espaço e que o formam, também são os corpos que operam a câmera a fim de representá-lo. É, portanto, relevante compreender o espaço filmado como resultado de uma ação dos corpos, diante e detrás da câmera.

O que caracteriza a imagem cinematográfica como tal é a reprodução do movimento. A leitura dos movimentos a partir do quadro cinematográfico gera fortes aproximações com a noção de espaço no campo da arquitetura e do urbanismo. Como visto, a noção temporal, decorrente do percurso dos corpos pelo espaço é crucial para sua apreciação. Dessa forma, a representação cinematográfica se firma como registro, não somente do espaço, mas também do tempo. 
Defende-se, aqui, que para a utilização do cinema como meio para representar o espaço, bem como instrumento de análise de seus aspectos físico-espaciais e socioculturais, se faz necessário compreender as relações que o cineasta estabelece com o meio que filma. Isso significa dizer que o corpo atrás da câmera e os corpos filmados não estão alheios às condições que viabilizam sua representação fílmica e, por sua vez, são impressas no enquadramento.

Todo filme pressupõe um corpo que filma e esse corpo é sempre munido de um aparelho. Por isso, nos filmes, a relação entre corpo, quadro e espaço, condicionadas pelo aparelho empregado para tal, permite leituras sobre o próprio tempo e espaço presentes na representação cinematográfica. As estratégias de representação do espaço estão extremamente fundamentadas em como o corpo do cineasta interage com ele, o que escolhe apresentar nos limites do seu quadro e que aparato utiliza para esse fim.

\section{Referências}

ARNHEIM, Rudolf. Arte e Percepção Visual. Uma Psicologia da Visão Criadora. 1. ed. São Paulo: Cengage, 1980.

AUMONT, Jacques. A Imagem. Campinas: Papirus, 1993.

A estética do filme. Campinas: Papirus, 1995.

BARBOSA, Jorge Luiz. A arte de representar como reconhecimento do mundo: o espaço geográfico, o cinema eo imaginário social. GEOgraphia, v. 2, n. 3, p. 69-88, 2000.

BARTHES, Roland. A câmara clara: nota sobre a fotografia. Rio de Janeiro: Nova Fronteira, 2015.

BAZIN, André. O Cinema - Ensaios. São Paulo: Brasiliense, 1991.

CORRÊA, Roberto Lobato. O espaço urbano. São Paulo: Ática, 1993.

CULLEN, Gordon. Paisagem urbana. São Paulo: Martins Fontes, 1983.

EISENSTEIN, Sergei. A forma do filme. Rio de Janeiro: Jorge Zahar Editor, 1990a.

O sentido do filme. Rio de Janeiro: Jorge Zahar Editor, 1990b.

FLUSSER, Vilém. Filosofia da caixa preta: ensaios para uma futura filosofia da fotografia. $1^{\text {a }}$ ed. São Paulo: Annablume, 2011.

Comunicologia. Reflexões sobre o futuro. São Paulo: Martins Fontes, 2015.

SANTOS, Milton. A natureza do espaço. Técnica e tempo. Razão e emoção. $4^{\text {a }}$ Edição ed. São Paulo: Editora da Universidade de São Paulo, 2006.

SENNETT, Richard. Carne e pedra: o corpo e a cidade na civilização ocidental. 4. ed. Rio de Janeiro: Best Bolso, 2016.

SHIEL, Mark.; FITZMAURICE, Tony. Screening the city. London / New York: Verso, 2003.

VANOYE, Francis.; GOLIOT-LÉTÉ, Anne. Ensaio sobre a análise fílmica. Campinas: Papirus, 2005.

ZEVI, Bruno. Saber ver arquitetura. 5ª Edição ed. São Paulo: Martins Fontes, 1996. 